\title{
15
}

\section{Characterization and Comparison of Sediments from Four Stormwater Ponds}

\author{
Oi Lun Li, Yiping Guo and Jen-Shih Chang
}

The Ontario Ministry of the Environment and the United States Environmental Protection Agency have singled out contaminated sediments as a major environmental problem. Many previous studies have evaluated the types and concentrations of contaminants captured in urban stormwater detention ponds. It was found that the concentrations of regulated compounds in sludge/sediments from stormwater detention ponds exceeded the Lowest Effect Level (LEL) of the Guidelines for the Protection and Management of Aquatic Sediment in Ontario. This study focused on the evaluation of the characteristics of stormwater sediments from different types of neighbourhoods. Neutron Activation Analysis (NAA) was used in the analysis of the compositions of sediments. Four different stormwater ponds around the cities of Burlington and Hamilton, Ontario, Canada were sampled in the summer of 2005. Two ponds are located in residential areas, one is located in highway/commercial areas and the other is located in commercial/light industrial areas. Our measurement shows that the particle sizes range from $20 \mu \mathrm{m}$ to $1258 \mu \mathrm{m}$ and the particles had irregular shapes. Thirty-two elements were found in the sediments and nine among these thirty-two elements were below the NAA detection limit. Seven elements were detected with a concentration higher than $1000 \mathrm{ppm}$, six elements had a concentration between $100 \mathrm{ppm}$ and $1000 \mathrm{ppm}$, and the remaining ten elements had a concentration lower than 100ppm. The main compositions (above 1000ppm) of the dried sludge included $\mathrm{Ca}>\mathrm{Al}>\mathrm{Fe}>\mathrm{K}>\mathrm{Mg}>\mathrm{Na}$

Li, O.L., Y. Guo and J. Chang. 2008. "Characterization and Comparison of Sediments from Four Stormwater Ponds." Journal of Water Management Modeling R228-15. doi: 10.14796/JWMM.R228-15. (C) CHI 2008 www.chijournal.org ISSN: 2292-6062 (Formerly in Reliable Modeling of Urban Water Systems. ISBN: 978-0-9808853-0-9) 
$>$ Ti. The trace compositions (below $1000 \mathrm{ppm}$ ) included $\mathrm{Mn}>\mathrm{Cl}>\mathrm{Ba}>\mathrm{Sr}$ $>\mathrm{Zn}>\mathrm{Cr}>\mathrm{V}>\mathrm{La}>\mathrm{Nd}>\mathrm{As}>\mathrm{Co}>\mathrm{Sc}>\mathrm{Br}>\mathrm{Sm}>\mathrm{Th}>$ Eu. Five regulated elements were detected by NAA. The concentrations of $\mathrm{Cr}, \mathrm{Fe}, \mathrm{Mn}$ and $\mathrm{Zn}$ in a residential area pond were higher than the LEL; the concentrations of $\mathrm{Fe}, \mathrm{Mn}, \mathrm{Zn}$ and $\mathrm{As}$ in another residential area pond were higher than the LEL while the concentration of $\mathrm{Cr}$ in the second residential area pond was above the SEL. The concentrations of Fe, $\mathrm{Zn}, \mathrm{Mn}$ and $\mathrm{As}$ in a highway/commercial area pond were higher than the LEL while the concentration of $\mathrm{Cr}$ there was above the SEL. The concentrations of $\mathrm{Fe}, \mathrm{Zn}$, $\mathrm{Mn}$ and As in a commercial/light industrial area pond were higher than the LEL and the concentration of $\mathrm{Cr}$ there was higher than the SEL.

\subsection{Introduction}

The quality of the stormwater pond sediments is dependent on the surrounding environment. Source areas such as parking lots, rooftops, streets and landscaped areas have important effects on stormwater sediment properties. The characteristics of stormwater sediment (sludge) are not uniform throughout a region, and they may vary by age of development or location in a city (USEPA, 1983; USEPA, 2004). Contaminated sediments have been singled out as a major environmental problem by the Ontario Ministry of the Environment. The Sediment Quality Guidelines (MOEE, 1993) are established to protect the aquatic environment by setting safe levels for metals, nutrients (substances which promote the growth of algae) and organic compounds. The Guidelines are designed to help environmental managers to distinguish the quality of sediment. The Guidelines establish three levels of effect - No effect level (NEL), Lowest Effect Level (LEL) and Severe Effect Level (SEL). The Sediment Quality Guidelines state that LEL is the level at which actual ecotoxic effects become apparent, where SEL represents contaminant levels in sediments that could potentially eliminate most of the benthic organisms. The concentrations of metal and organic contaminants exceeding the LEL could endanger the organisms that live or feed in the sediments (MOEE, 1993). The sediments may need further testing and treatment if the results of regulated elements exceed the LEL. Guidelines of the LEL and SEL for metals by the Protection and Management of Aquatic Sediment in Ontario are shown in Table 15.1.

In 1997 and 1998, Environment Canada conducted a study to evaluate the sediment accumulating in stormwater ponds and the effects of contaminants in the pond on wildlife health (Environment Canada, 1999). 
Six stormwater ponds in the Greater Toronto Area (GTA) and nine stormwater ponds in the city of Guelph were studied. The types of catchment area draining to these stormwater ponds are divided into four groups: residential, commercial, commercial/light industrial and residential/ commercial. Twelve ponds are located in residential areas. The remaining three ponds are located respectively in commercial areas, commercial/light industrial areas and residential/commercial areas. GTA ponds were sampled in July and Guelph ponds were sampled in September. Sediments from 14 of 15 ponds contained concentrations of contaminants that exceeded the LEL of the Sediment Quality Guidelines and the Guidelines for the Protection and Management of Aquatic Sediments in Ontario (Persaud et al., 1992). The assessment of total metals in most pond sediments against the Sediment Quality Guidelines indicates a marginal-to-significant pollution of $\mathrm{Cr}, \mathrm{Zn}$ and $\mathrm{Cu}$. Concentrations of PAHs and $\mathrm{Pb}$ in sediments exceeded the provincial LEL in six and seven ponds respectively. Sediments in one site (commercial/light industrial) were grossly polluted by $\mathrm{Cr}$, which exceeded the provincial guideline at the SEL (Environment Canada, 1999).

Another study tested sediments toxicity and chemistry of receiving water impacted by a variety of stormwater and CSO discharges in five areas (Rochfort et al., 2000). The assessment of total metals in the pond sediments against the MOEE Sediment Quality Guidelines indicates a marginal-tosignificant pollution by $\mathrm{As}, \mathrm{Cu}, \mathrm{Fe}, \mathrm{Hg}, \mathrm{Mn}, \mathrm{Ni}, \mathrm{Pb}$ and $\mathrm{Zn}$ in a stormwater pond located in the residential areas of Richmond Hill, Ontario. A marginalto-significant pollution by $\mathrm{As}, \mathrm{Cr}, \mathrm{Cu}, \mathrm{Mn}, \mathrm{Nil}$ and $\mathrm{Zn}$ is found in a stormwater pond located near Highway 401 in Toronto, Ontario as well (Marsalek et al., 1997).

In all of the above-reviewed studies, samples of sediments were analyzed by inductively coupled plasma (ICP). ICP requires the calibration of each element for every experiment. Poor stability of the medium and lengthy process severely complicates the calibration procedures, especially where changes in sensitivity with time vary across the spectrum (Gray, 1994). A considerable amount of work needs to be done for each experiment. Also, the sample is often digested by the addition of different chemicals and concentrates down to a known volume before analysis by ICP (Bishop et al., 2000). The Neutron Activation Analysis (NAA) facility inside the McMaster Nuclear Reactor is an extremely sensitive multi-element analysis technique with great accuracy and precision. It is a non-destructive analysis that allows determination of many elements simultaneously at trace levels. This technique does not need any irradiation chemical treatment, thus the results are free from blank error caused by reagents (Soete et al., 1972).

Li, Guo and Chang. Characterization and Comparison of Sediments from Four Stormwater Ponds. In: Reliable Modeling of Urban Water Systems, Monograph 16 ISBN-978-0-9808853-0-9. C CHI 2008.

www.computationalhydraulics.com 
Although previous studies observed that the sediments of the stormwater ponds in Ontario were contaminated, the precision of earlier measurements using ICP is relatively low compared to NAA, and the effect of the surrounding neighborhoods to the sediment characteristics is worthy of further investigation. This study evaluates the characteristics of the stormwater sediments from different types of neighborhoods using NAA. The types of neighborhoods included residential areas, commercial areas and highway areas. The results were also compared to the Guidelines for the Protection and Management of Aquatic Sediment in Ontario.

Table 15.1 Guidelines for (metals only) the Protection and Management of Aquatic Sediment in Ontario (MOEE, 1993)

\begin{tabular}{ccc}
\hline Elements & LEL $(\mu \mathrm{g} / \mathrm{g})$ & SEL $(\mu \mathrm{g} / \mathrm{g})$ \\
\hline Iron & 20000 & 40000 \\
Manganese & 460 & 1100 \\
Zinc & 120 & 820 \\
Lead & 31 & 250 \\
Chromium & 26 & 110 \\
Copper & 16 & 110 \\
Nickel & 16 & 75 \\
Arsenic & 6 & 32 \\
Cadmium & 0.6 & 10 \\
Mercury & 0.2 & 2 \\
\hline
\end{tabular}

\subsection{Locations of Sampling Sites}

Four different stormwater ponds around the cities of Burlington and Hamilton, Ontario were sampled in the summer of 2005. In estimating the average imperviousness of land areas, the typical imperviousness of different housing types (e.g. single detached, townhouses, etc.) were used as basis. The estimated values are rough approximations only; they were obtained for a relative comparison between the four sites. A summary of the main characteristics of the four sites is presented in Table 15.2. The details of the ponds and their upstream areas are described below. 


\subsubsection{Parkside Road Site}

Parkside Road pond is bounded by Highway No. 5 (Dundas Street) to the south and Parkside Drive to the north in the Town of Flamborough, Ontario. It is on the east side of the newly developed Waterdown settlement area. The drainage area of the pond is about $31.6 \mathrm{ha}$, and it was designed to control runoff from upstream residential areas. Based on the maps showing land-use types and the stormwater management design report for the pond, the average imperviousness of the upstream area was estimated to be about 0.4.

\subsubsection{Waterdown Road Site}

The Waterdown Road pond services the Rockview summit subdivision which is located in a section of Lot 11, Concession 3, former Geographic Township of east Flamborough, now in the Town of Flamborough. It is bounded by a residential subdivision to the east, Highway No. 5 (Dundas street) and Belmont residential subdivision to the north; proposed industrial/business parks to the west and conservation lands and Niagara Escarpment to the south.

The Rockview subdivision is located within the Grindstone Creek drainage basin, it has one block for street townhouses and two blocks for multiple family dwellings. The total area is approximately fourteen hectares. The site is well drained and generally slopes to the south towards the Niagara escarpment. The average imperviousness of this area was estimated to be about 0.55 .

\subsubsection{Dartnell Road Site}

The Dartnell Road pond is located at the Dartnell Road Interchange of the Lincoln Alexander Parkway in the city of Hamilton, Ontario. In addition to portions of the highway, the pond services mainly commercial areas and the average imperviousness of the upstream area was estimated to be approximately 0.36 .

\subsubsection{Ancaster Soccer Field Site}

The Ancaster Soccer field pond is located in the city of Hamilton, Ontario. The pond is bounded by Golf Links Road, Meadowlands Blvd, a shopping mall and a soccer field. The total area of the facility itself is 3.15 ha. The 
pond is mainly used for flood control. The upstream area comprises largely commercial/industrial lands and the average imperviousness was estimated to be approximately 0.65 .

Table 15.2 Area types and average imperviousness of each site.

\begin{tabular}{ccccc}
\hline & Dartnell & Parkside & Waterdown & Ancaster \\
\hline Area Type & & Residential & Single- & Light \\
& Highway/ & areas/ & family / & industry / \\
& commercial & Single- & business & residential \\
& areas & family & park areas & areas \\
Imperviousness & 0.36 & 0.4 & 0.55 & 0.65 \\
\hline
\end{tabular}

\subsection{Sampling and Analysis Methodology}

\subsubsection{Sampling Procedure}

Sludge samples from the four sites were obtained with the help of the West Central Region of the Ontario Ministry of Environment. Their field personnel (Mr. Brian Thorburn) did the actual sampling and their field procedures were followed. Surficial sediments (top $5 \mathrm{~cm}$ ) were collected with a steel scoop and tray. The equipment was first washed with hexane in order to elute possible contaminants. Approximately five samples were taken at different locations within each pond. Out of the five samples for each pond, at least one from the forebay and one from the outlet were taken. The samples from the four ponds were taken on the same day and represent a snapshot condition of the ponds. For each pond, samples from different locations were well mixed in a tray and then put into eight $250 \mathrm{ml}$ bottles. The sealed bottles were kept in a freezer at $4^{\circ} \mathrm{C}$ before analyses.

\subsubsection{Multi-element Measurement by Neutron Activation Analysis}

\section{Theory of Neutron Activation Analysis (NAA)}

Three liters of sludge were naturally dried at room temperature under a fume hood and put into a $10 \mathrm{~g}$ container. The samples were irradiated in the core of the nuclear reactor. Figure 15.1 shows the principle of NAA. Neutrons are injected into a sample and interact with a target nucleus by a non-elastic 
collision, and compound nuclei are formed in a highly excited state. The excited nuclei emit nuclear particles or prompt gamma rays and undergo a rapid de-excitation to a more stable configuration, typically within 10-14 sec. The new nuclei are radioactive and will further de-excite by emitting decay gamma rays with a specific energy depending upon each composition and element. The NAA relies on the measurement of either the characteristic prompt or decay gamma rays for identifying elements and determining their amounts present in samples. The technique is flexible with respect to decay time for different nuclei. Elements can be separated into two categories: long-lived and short-lived. Nuclei that take more than $10 \mathrm{~h}$ to decay are called long-lived elements and the given reaction time would be longer. Nuclei that take less than a few hours to half decay are called short-lived. Long-lived nuclides are difficult to excite, therefore the irradiation time should be long enough. The delay time of long-lived elements is approximately one week. On the other hand, easily excited nuclides have a short half-life and therefore the cooling and counting time are less.

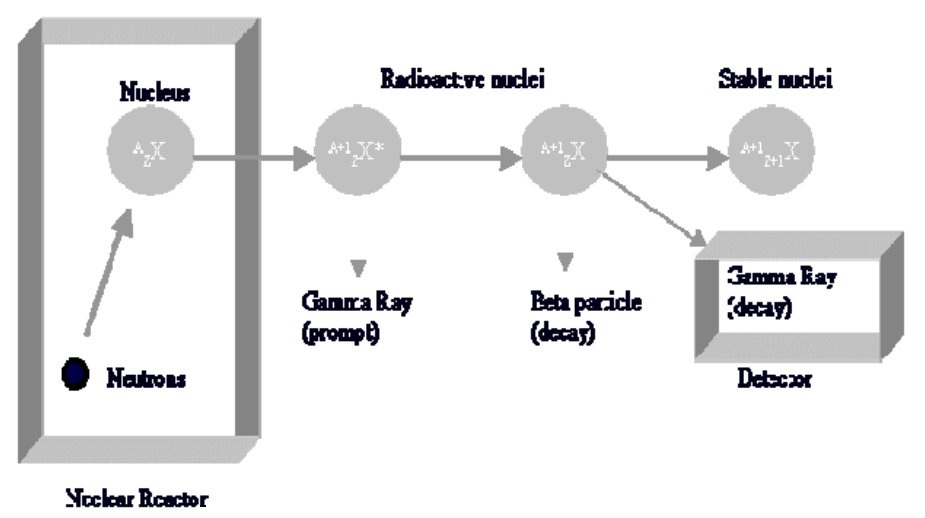

Figure 15.1 Principle of Neutron Activation Analysis,

The standard reference material (SRM) was used for the calibration of intensity and the evaluation of techniques employed in the analysis of coal and similar materials. The standards for the sludge are SRM 1632b and 1633b. SRM 1632b consists of a $50 \mathrm{~g}$ bottle of bituminous coal with a nominal sulfur content of $1.9 \%$. A unit of SRM $1633 \mathrm{~b}$ consists of $75 \mathrm{~g}$ of the same powdered material. The total error in each standard was calculated to be slightly less than $1 \%$ at the $95 \%$ confidence level. 
Elements measured as below the detection limit indicate their existence but with unknown concentration. The expected major components of the sludge that could not be measured by the present NAA system are $\mathrm{Si}, \mathrm{C}, \mathrm{N}$, $\mathrm{O}, \mathrm{Cu}, \mathrm{Pb}$ and $\mathrm{H}$. Most of these elements are difficult to excite by nuclei. Special techniques combined with the current NAA system are necessary.

\section{Advantages of Neutron Activation Analysis}

The NAA facility inside the McMaster Nuclear Reactor was used for stormwater sludge composition analyses. As this technique does not need irradiation or chemical treatment for the analysis, it is free from blank error caused by the use of contaminated reagents and eliminates the necessity for rigorous microchemical procedures in the determination of trace constituents. Its non-destructive analysis allows determination of many elements simultaneously at trace levels (Soete at el., 1972).

These advantages of NAA make it compatible to other method of analysis. Inductively Coupled Plasma (ICP), the most common optical measurement used for analysis of sediment compositions, requires calibration of elements for each analysis. Trace element determinations are usually required in the presence of significantly greater concentrations of other elements. In order to obtain the best determination limits for the elements, a minimum sample dilution must be used. Poor stability in the medium and lengthy time requirement severely complicate the calibration procedures, especially where changes in sensitivity with time vary across the spectrum (Gray, 1994). Also, samples are often digested by the addition of different chemicals and concentrate down to a known volume before analysis by ICP (Bishop et al., 2000). This might cause possible contamination of samples. Although ICP is capable of analyzing more elements than NAA, the complicated calibration procedure is the main drawback for this method. Other optical techniques such as DC arc Plasma and RF Arc plasma require calibration for measurements as well. Other radiation techniques, such as Proton Induced X-ray Emission (PIXE) and Xray fluorescence, are also used in many applications. X-ray fluorescence is capable of measuring some of the oxides in the samples as well. However, these methods can only be used for a limited number of elements.

\section{Limitations of Neutron Activation Analysis}

NAA does not give any information about the chemical form in which a particular element is present. Also, statistical errors occur when the element is near the limit of detection. These errors are related to the fluctuations 
associated with the statistical character of nuclear disintegrations. The chemical and instrumental methods used in activation analysis are relatively simple and inexpensive, but the irradiation stage of the technique requires access to a nuclear reactor or some other source of sub-atomic particles or radiations (Soete et al., 1972). Since McMaster University has a nuclear reactor, the marginal cost of providing irradiation facilities is quite small.

\subsubsection{Particle Size and Shape Measurement}

Wet samples were added into a laser diffraction particle sizing instrument (Malvern Mastersizer 2000, HydroS) in small portions. Fifteen measurements of different parts of the sludge were taken as the bottom part of the container of the sludge may contain heavier particles.

The physical properties of the sludge include the particle size distribution, image and shape of the particles. The dried sludge was observed by an optical microscope with a lens magnification of 320 (Leitz Wtzlar Germany) and a computer software "Nikon" was used to view the image of the particles (Malvern Instruments Ltd., 1997).

\subsubsection{Scanning Electron Microscope}

The Scanning Electron Microscope (SEM) is a microscope that uses electrons to form an image. Based on the conductivity of a sample, SEM produces images of high resolution. Figure 15.2 illustrates schematically the basic features of a scanning electron microscope. The electron source is located at the top. The electron beam comes from a filament which is made of various types of materials. The most common filament comes from the Tungsten hairpin gun. The filament is a loop of tungsten that functions as the cathode. The electrons emitted from the source are accelerated toward the anode due to the large potential between the filament and the anode. Some electrons accelerate right by the anode and continue down the column to the sample. The electron will experience both a force down the axis and another force radial from the condenser lens right after leaving the electron gun. The lens is used to control the beam current reaching the sample. The objective coils lens is used to resolve the final mean size and focus. The deflection coils are energized and create a magnetic field which deflects the beam back and forth in a controlled pattern. The distance from the bottom pole piece of the objective lens can be carried and allow the electron beams to scan the samples outside the magnetic field range of the lens. When the electron 
beam hits the sample, it produces secondary electrons. These electrons are collected by a backscatter detector and are converted to a voltage and amplified. For standard SEM imaging, the back-scattered electrons (BSE) and secondary electrons are detected, and the resulting signal is processed to yield a pixel in an image. Progressively, as the entire sample is scanned, an image of the sample is formed.

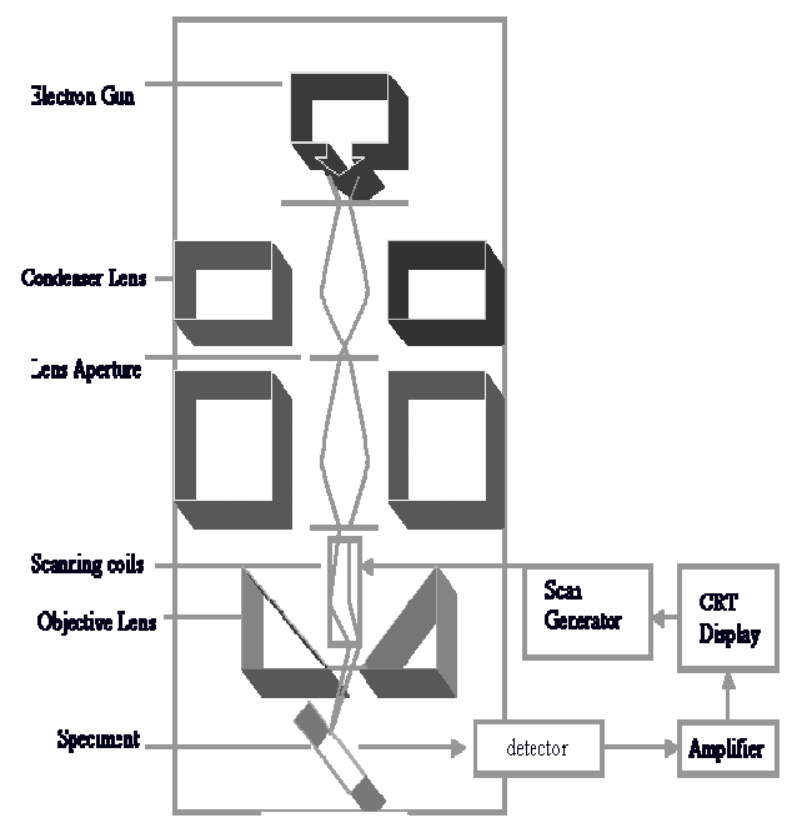

Figure 15.2 Schematic of scanning electron microscope

\subsection{Results}

\subsubsection{Particle Size Distribution}

Figures 15.3, 15.4, 15.5 and 15.6 show the particle size distributions for the Parkside Road, Waterdown Road, Dartnell Road and Ancaster soccer field stormwater pond respectively. The particle size distributions for Parkside 
road, Waterdown road and Dartnell road stormwater ponds were bimodal with maximum concentrations at $69 \mu \mathrm{m}, 45 \mu \mathrm{m}$ and $20 \mu \mathrm{m}$ and another peak concentration around $831 \mu \mathrm{m}, 1258 \mu \mathrm{m}$ and $831 \mu \mathrm{m}$ respectively. The particle size distribution for Ancaster soccer field stormwater pond had a maximum concentration at $20 \mu \mathrm{m}$.

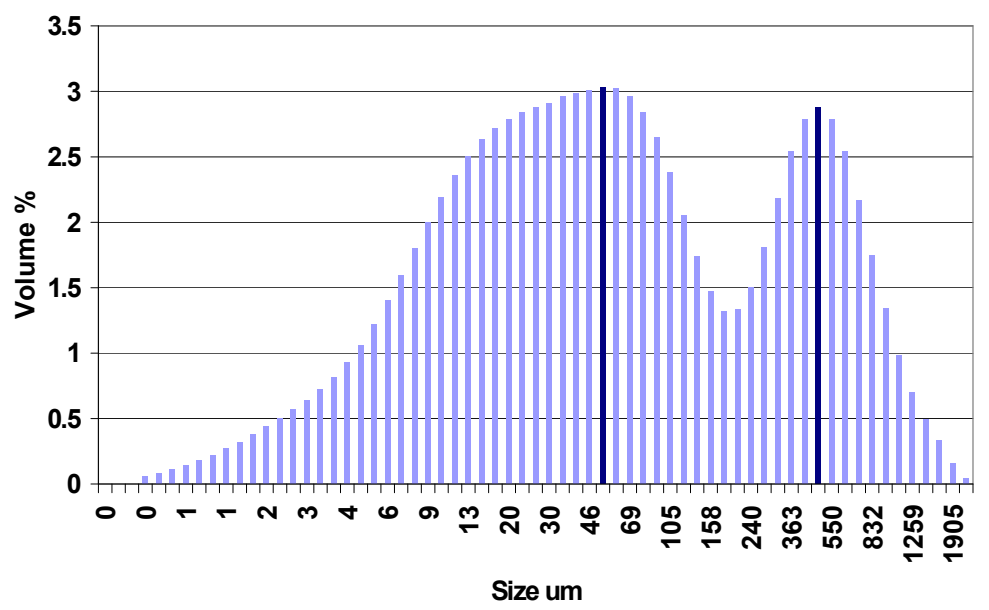

Figure 15.3 Particle size distribution for Parkside Road Stormwater Pond sampled in summer.

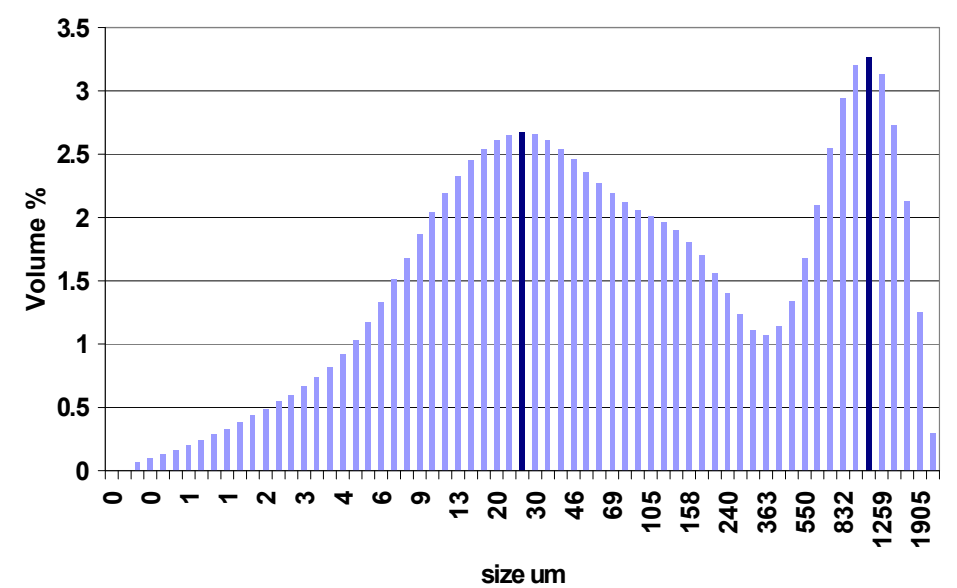

Figure 15.4 Particle size distribution for Waterdown Road Stormwater Pond sampled in summer. 


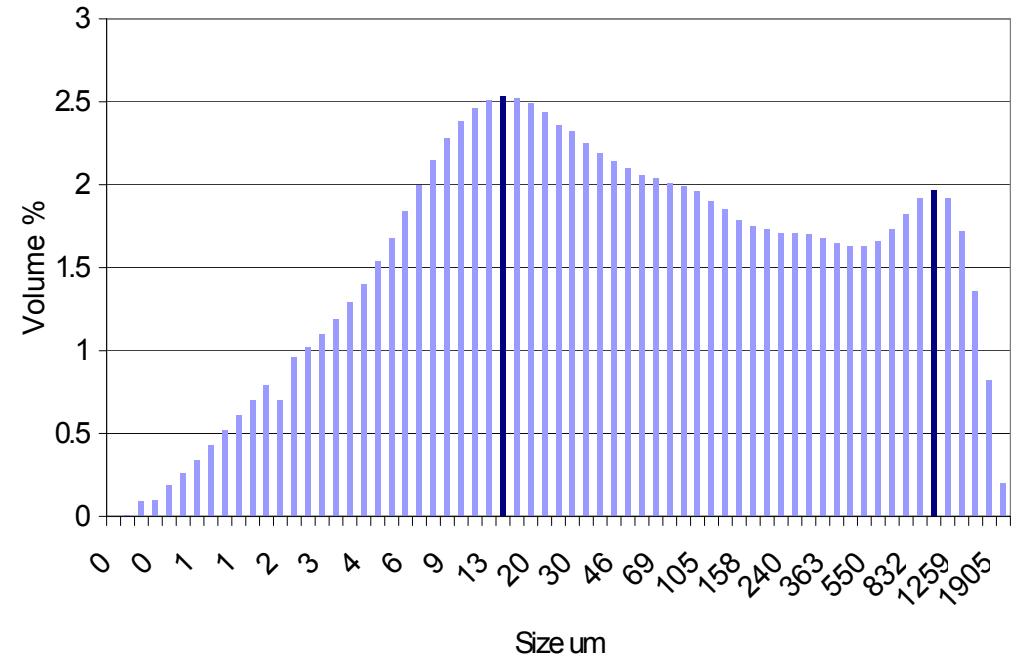

Figure 15.5 Particle size distribution for Dartnell Road Stormwater Pond sampled in summer.

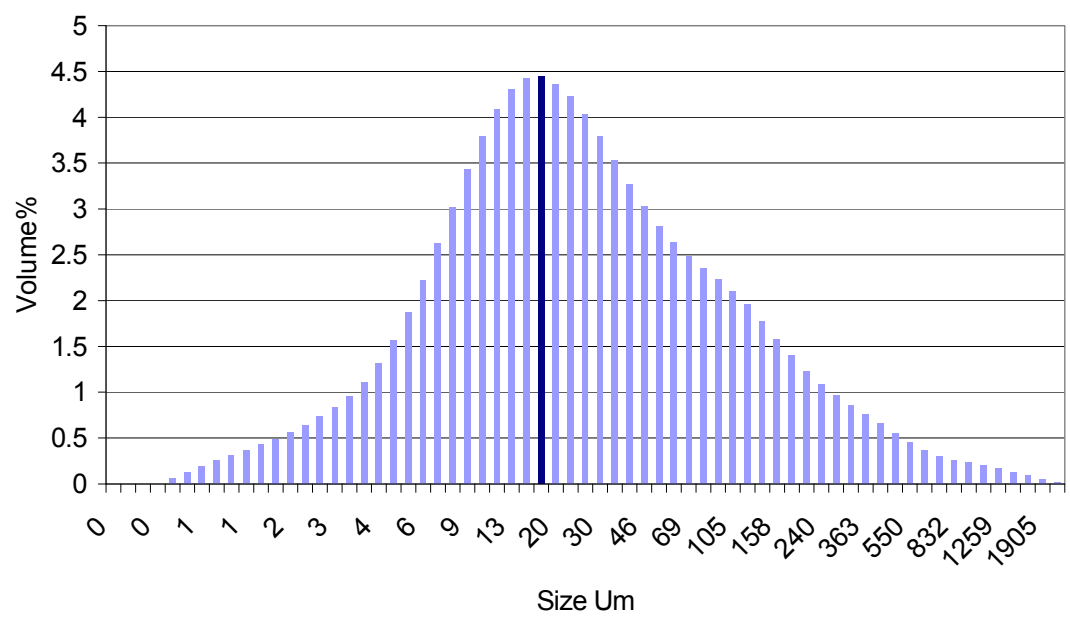

Figure 15.6 Particle size distribution for Ancaster Soccer Field Stormwater Pond sampled in summer. 


\subsubsection{Particle Image}

Optical images of dried sludge in the stormwater ponds were observed using an optical microscope and SEM. Figure 15.7 shows the typical irregular particle shape in the dried sludge. The particle size measurement from an optical microscope was obtained by roughly comparing the image of the particles to a scale, and the image was projected at two dimensions. Figure 15.8 shows the SEM image of particles with higher resolution and a magnification of 1000 times. Some large particles were aggregations of smaller particles. The sizes of the particles range from $20 \mu \mathrm{m}$ to $1600 \mu \mathrm{m}$. In addition to reporting the images of particles, we used an optical microscope and a SEM to demonstrate that an approximate measurement of particle sizes may also be quickly made using these instruments.

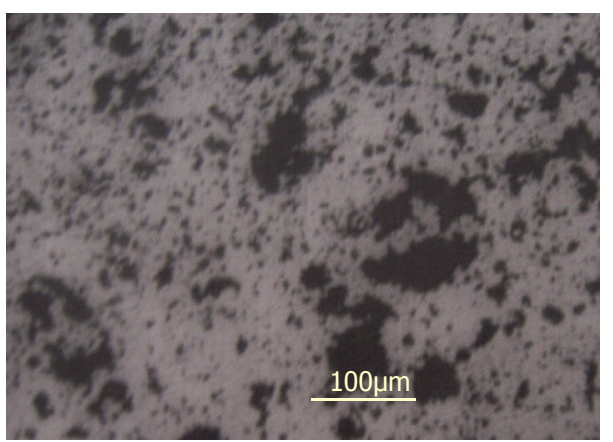

Figure 15.7 Typical image of dried sludge from Dartnell Rd stormwater pond

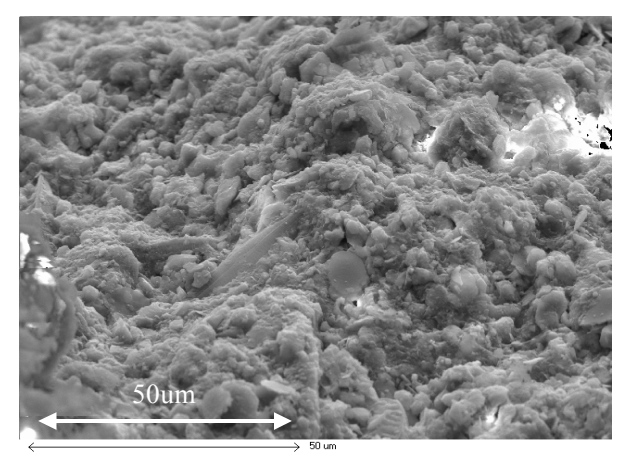

Figure 15.8 SEM image of dried sludge from Dartnell Rd stormwater pond 


\subsubsection{Elements in Stormwater Sediments}

Thirty-two elements were observed in the sediment of which nine were below detection limit. Comparisons between the concentrations of each element in the sediments from the four stormwater ponds are shown in Figures 15.9, 15.10 and 15.11, which show the concentration ranges of $1000 \mathrm{ppm}$ and above, from $100 \mathrm{ppm}$ to $1000 \mathrm{ppm}$, and below $100 \mathrm{ppm}$, respectively. Nine elements were detected with a concentration higher than $1000 \mathrm{ppm}$, four elements had a concentration between 1000ppm and $100 \mathrm{ppm}$, and the remaining ten elements had a concentration lower than $100 \mathrm{ppm}$. The main compositions (above 1000ppm) of the dried sludge include $\mathrm{Ca}>\mathrm{Al}>\mathrm{Fe}>\mathrm{K}>\mathrm{Mg}>\mathrm{Na}>\mathrm{Ti}>\mathrm{Mn}$. The trace compositions (below 1000ppm) include $\mathrm{Cl}>\mathrm{Zn}>\mathrm{Ba}>\mathrm{Sr}>\mathrm{Cr}>\mathrm{V}>\mathrm{La}>\mathrm{Nd}>\mathrm{As}>\mathrm{Br}$ $>\mathrm{Co}>\mathrm{Sc}>\mathrm{Th}>\mathrm{Sb}>\mathrm{Sm}>\mathrm{Eu}$. Since the concentrations of each element from the four sites vary, the order is a general ranking only. Most elements have quite similar concentrations between the four sites, a few elements such as $\mathrm{Ca}, \mathrm{Mg}, \mathrm{Cr}, \mathrm{Zn}$ and $\mathrm{Cl}$ vary greatly between sites.

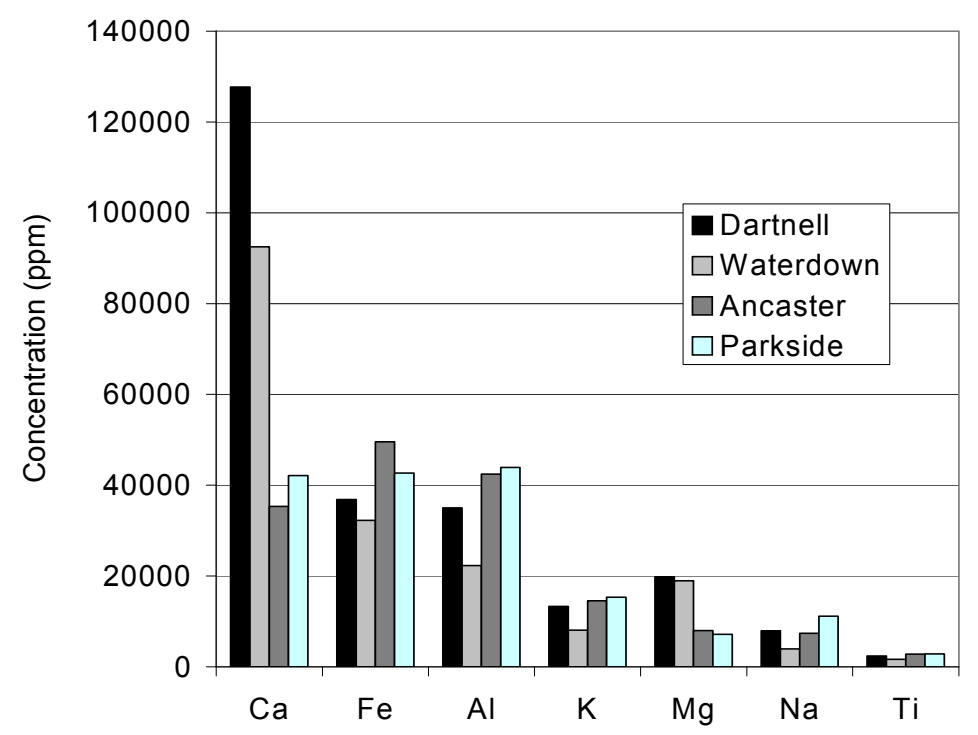

Figure 15.9 Concentrations of elements above 1000ppm 


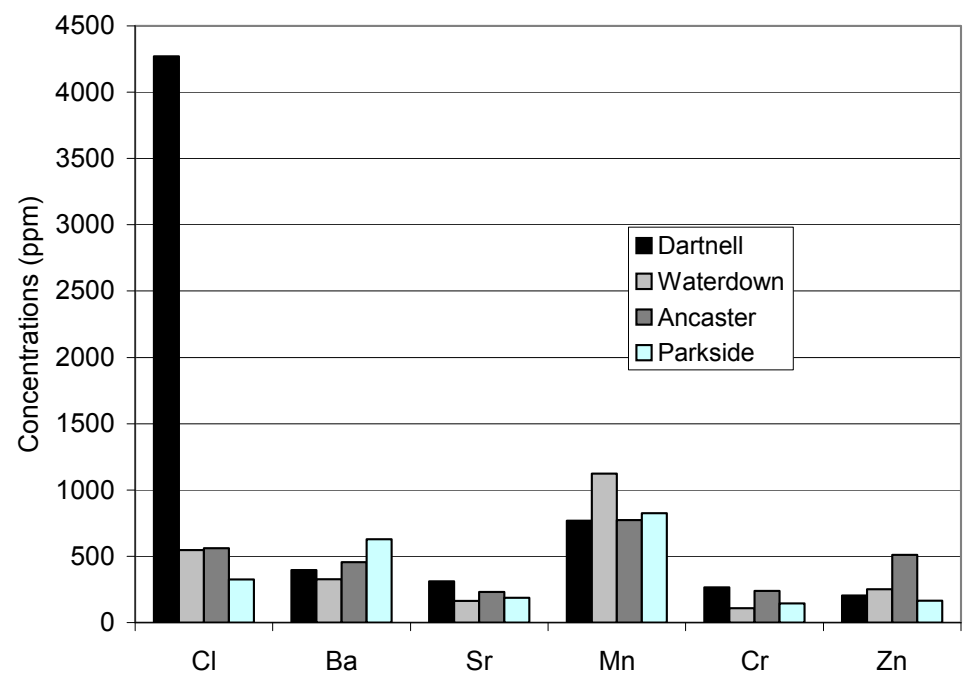

Figure 15.10 Concentrations of elements between 100ppm and 1000ppm.

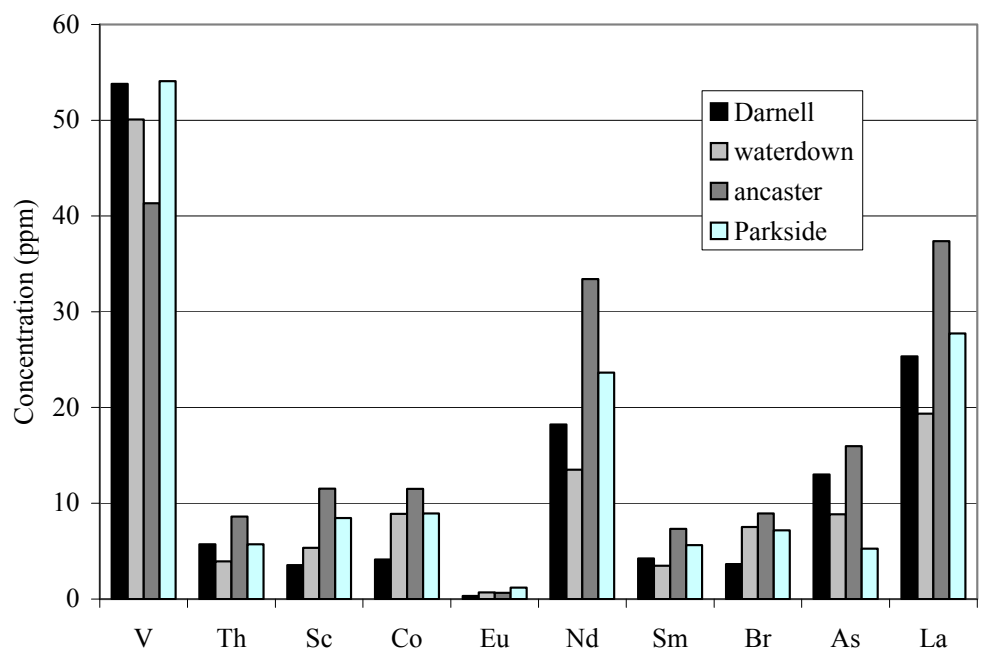

Figure 15.11 Concentrations of elements lower than 100ppm. 


\subsection{Discussion}

The sediment characteristics of two stormwater ponds located in residential areas, one in highway areas and one in commercial areas were compared. The sediment particle size distributions for Parkside Road, Waterdown Road and Dartnell Road stormwater ponds were bimodal with maximum concentrations at $69 \mu \mathrm{m}, 45 \mu \mathrm{m}$ and $20 \mu \mathrm{m}$ and secondary peak concentrations around $831 \mu \mathrm{m}, 1258 \mu \mathrm{m}$ and $831 \mu \mathrm{m}$, respectively. The sediment particle size distribution for Ancaster soccer field stormwater pond was single mode with a maximum concentration at $20 \mu \mathrm{m}$. Parkside Road and Waterdown Road sites are both located in the same residential areas, and the particle size distributions of the two ponds were similar. The particle size distribution in the Dartnell site was similar to the two residential area sites while only small particles were present in the Ancaster soccer field stormwater pond.

A previous study suggested that land use affects the particle size distribution of sediments in stormwater ponds to some degree (Liebens, 2001; Ha and Stenstrom, 2002). Commercial streets are usually swept more often than residential streets. However, the rotary brush street sweepers are incapable of picking up fine materials such as clay and silt (Young et al., 1996; Kidwell-Ross, 1988; Brinkmann et al., 1999). Street sweeping around Ancaster soccer field stormwater pond, which is located at a commercial area, can probably remove most of the larger size particles but not the fine particles. Thus only one peak with small particle size appears in the particle size distribution for this site. Litter and waste from the mall also increase the volume of particles, as observed in Figure 15.5.

Five regulated elements were detected by NAA. Table 15.3 shows the concentrations of $\mathrm{Cr}, \mathrm{Fe}, \mathrm{Zn}$, As and $\mathrm{Mn}$ of each pond as compared to the LEL and SEL. The assessment of $\mathrm{Zn}$ and $\mathrm{Mn}$ in all ponds against the MOEE sediment quality guidelines indicates a marginal-to-significant pollution. The concentrations of Fe in the Dartnell and Waterdown stormwater ponds indicate a marginal-to-significant pollution while the concentrations of $\mathrm{Fe}$ in the Ancaster and the Parkside stormwater pond indicate a gross pollution. The concentrations of $\mathrm{Cr}$ in all ponds except the Parkside stormwater pond indicate a gross pollution. The concentrations of As in all ponds except Parkside pond are above the LEL. These results are similar to the observations from the Greater Toronto Area (Persaud et al., 1992; Schroter, 1997; Skokouhian et al., 2001). 
As shown in Figures 15.9, 15.10 and 15.11, the common main compositions (above 1000ppm) of the dried sediments in the four stormwater ponds include $\mathrm{Ca}>\mathrm{Al}>\mathrm{Fe}>\mathrm{K}>\mathrm{Mg}>\mathrm{Na}>\mathrm{Ti}>\mathrm{Mn}$, and the trace compositions (below 1000ppm) include $\mathrm{Cl}>\mathrm{Zn}>\mathrm{Ba}>\mathrm{Sr}>\mathrm{Cr}>\mathrm{V}>$ $\mathrm{La}>\mathrm{Nd}>\mathrm{As}>\mathrm{Br}>\mathrm{Co}>\mathrm{Sc}>\mathrm{Th}>\mathrm{Sb}>\mathrm{Sm}>\mathrm{Eu}$. Among all of the elements, the concentrations of $\mathrm{Ca}, \mathrm{Cr}, \mathrm{Zn}$ and $\mathrm{Cl}$ in the four ponds vary the most. Other elements have similar concentrations between sites.

A large variation between the concentrations of $\mathrm{Cr}, \mathrm{Zn}, \mathrm{Mg}$ and $\mathrm{Ca}$ is observed in the sediments obtained from the two stormwater ponds located in the same residential area. The main differences between the two sites are traffic density and imperviousness of the area. The Waterdown site is located beside a main road while the Parkside site is located inside a residential area. The road runoff clearly affects the Waterdown site. With higher traffic density and imperviousness, the Waterdown site has higher concentrations of $\mathrm{Cr}, \mathrm{Zn}, \mathrm{Mg}$ and $\mathrm{Ca}$.

It is within expectations that higher levels of $\mathrm{Cr}$ and $\mathrm{Zn}$ were observed in the Ancaster site, which is located in commercial/light industrial areas. It can be explained by several industrial applications of both metals. For example, $\mathrm{Cr}$ is used in steel, in plating and as a pigment in glass; $\mathrm{Zn}$ is used as a pigment and car tires (Liebens, 2001). Our result agrees with the findings reported in the Great Lakes Fact Sheet by Environment Canada (Great Lakes Fact Sheet, 1999). The average concentration of $\mathrm{Cr}$ in light industrial/commercial areas was highest among the 14 sites sampled in the Greater Toronto Area and the city of Guelph, while the concentration of $\mathrm{Zn}$ from industrial/commercial areas was also higher than the average concentrations measured in residential areas.

The addition of road salts may be a major reason for the high concentrations of $\mathrm{Cl}$ in the Dartnell Road site. Road salts are used as deicing and anti-icing chemicals for winter road maintenance (Barret, 1998; Legret, 2006). The road salts in use are mainly chloride salts, including sodium chloride $(\mathrm{NaCl})$, calcium chloride $\left(\mathrm{CaCl}_{2}\right)$, magnesium chloride $\left(\mathrm{MgCl}_{2}\right)$ and Potassium chloride (KCl) (Environment Canada, 2004). As the Dartnell site is located beside Lincoln Alexander Parkway, large amount of de-icing chemicals can be found in the sediments. Thomson et al. (1997) indicated that highway runoff generally contains solids, including de-icing agents, heavy metals and petroleum hydrocarbons. Metal-chloride compounds from industrial and automobile emissions are other possible sources of $\mathrm{Cl}$. Altogether with the deicing agent applied to the highway areas, it may explain the present of high concentration of $\mathrm{Cl}$ in the sample. Marsalek et al. (1997) also found high levels of contamination of heavy 
metals and PAHs in highway runoff. This agrees with the results shown in Table 15.3. It is shown in Table 15.3 that the concentrations of five regulated heavy metals are all above the LEL in the sediments from the Dartnell site.

Table 15.3 Comparison of the concentrations of $\mathrm{Cr}, \mathrm{Fe}, \mathrm{An}, \mathrm{As}$ and $\mathrm{Mn}$ in four stormwater ponds to the LEL and SEL levels.

\begin{tabular}{ccccccc}
\hline & $\begin{array}{c}\text { LEL } \\
\mu \mathrm{g} / \mathrm{g}\end{array}$ & SEL $\mu \mathrm{g} / \mathrm{g}$ & Dartnell & Parkside & Waterdown & Ancaster \\
\hline Imper- & & & 0.36 & 0.4 & 0.55 & 0.65 \\
viouness & & & & & & \\
\hline $\mathrm{Fe}$ & 20000 & 40000 & 24441 & 42673 & 32289 & 49560 \\
$\mathrm{Mn}$ & 460 & 1100 & 768 & 825 & 1090 & 772 \\
$\mathrm{Zn}$ & 120 & 820 & 204 & 165 & 251 & 511 \\
$\mathrm{Cr}$ & 26 & 110 & 265 & 109 & 144 & 239 \\
$\mathrm{As}$ & 6 & 32 & 13 & 5 & 9 & 16 \\
\hline
\end{tabular}

\subsection{Conclusions}

The sediments from the four stormwater ponds were found to have some similar and some different characteristics. The particle size distributions of Parkside Road site, Waterdown Road site and Dartnell Road site have peaks at $69 \mu \mathrm{m}, 45 \mu \mathrm{m}$ and $20 \mu \mathrm{m}$ and secondary peaks at around $831 \mu \mathrm{m}, 1258$ $\mu \mathrm{m}$ and $831 \mu \mathrm{m}$, respectively. The particle size distribution of the Ancastor soccer field stormwater pond has a single maximum concentration at $20 \mu \mathrm{m}$. The particle shapes are irregular. Parkside Road and Waterdown Road stormwater ponds are both located in the same residential areas, and the particle size distributions of the two ponds are similar. Larger particles were observed in the Dartnell Road stormwater ponds. This pond is located in a highway/commercial area and might be affected by the effect of snow removal and de-icing operations during the winter. Smaller particles were present in the Ancaster soccer field stormwater pond. That site also has the highest volume percentage of particles probably due to decomposed litter or garbage from a nearby shopping mall. Street sweeping around the commercial area removes many of the larger particles, thus most of the particles in the Ancaster soccer field stormwater pond are small. 
Five regulated elements including $\mathrm{Cr}, \mathrm{Fe}, \mathrm{Zn}$, As and $\mathrm{Mn}$ were detected by NAA. Most of the regulated elements in the four sites were at least above LEL. High levels of $\mathrm{Cr}$ and $\mathrm{Zn}$ were observed in the Ancaster site (located in a commercial/light industrial area) where the concentration of $\mathrm{Cr}$ was higher than SEL. Highest concentration of $\mathrm{Cl}$ was observed in highway/commercial areas which related to the deicing agent and other contaminants from highway runoff. Different concentrations of $\mathrm{Ca}, \mathrm{Zn}, \mathrm{Cr}$ and $\mathrm{Mg}$ were found in the two residential area stormwater ponds in the same town. Factors that could contribute to the differences might include traffic density and upstream area imperviousness. The Waterdown site, with higher traffic density and imperviousness, has a slightly higher concentration of heavy metals.

\section{Acknowledgments}

The authors thank M. Ara and other staff at McMaster Univieristy's Nuclear Research Building for their technical assistance; and A. A. Barbara and D. Brocile for their valuable comments. The assistance provided by $\mathrm{Mr}$. Michael Spencer and Mr. Brian Thorburn of the West Central Region of the Ontario Ministry of Environment is greatly appreciated. Financial support for this work is provided by the Natural Sciences and Engineering Research Council of Canada.

\section{References}

Barrett, M. E., Irish Jr., L. B, Malinia Jr., J. F., and Charbenuea, R. J., 1998. Characterization of highway runoff in Austin, Texas, Area. J. Environ. Eng., ASCE 124, pp. 131-137.

Brinkmann, R., Tobin, G. A., and Ryan, J., 1999. Street sweeping and stormwater runoff. Phase I: determining the most effective sweeper. Florida Department of Transportation District 7 Technical Report, Tampa, Florida.

Bishop, C. A., Struger, J., Shirose, L. J, Dunn, L., and Gampbell, G. D., 2000. Contamination and Wildlife Communities in Stromwater Detention Ponds in Guelph and the Great Toronto Area, Ontario, 1997 and 1998, Water Quality Research Journal of Canada, 35(3) pp.313-580

Environment Canada, 2004. Code of practice to reduce environmental impacts of road salts, Ottawa.

Gray, A. L., 1994. Inductively Coupled Plasma Mass Spectrometry in Maturity - What Problems Remains. Analytical Proceedings Including Analytical Communications. 31, pp. 371-375 
Great Lakes Fact Sheet, 1999. Stormwater detention ponds of Southern Ontario: Are they a risk to wildlife. Authority of the Minster of Environment, Minister of Public Works and Government Services Canada

Ha, H., and M. K. Stenstrom, 2002. Identification of land use with water quality data in stormwater using a neural network. Water Research,.37: pp.4222-4230

Kidwell-Ross, R., 1998; Port of Seattle commissions Sweeping Study. Am Sweeper 6(2), pp. $18-37$

Legret. M, C. Pagotto, 2006. Heavy metal deposition and soil pollution along two major rural highways. Environmental Technology.27: pp.247-254(8)

Lieben. J, 2001. Heavy metal contamination of sediments in stormwater management systems: the effect of land use, particle size, and age. Environmental Geology. 41, pp. 341-351

Ministry of the Environment, 1993. Guidelines for the Protection and Management of Aquatic Sediment Quality in Ontario, Ministry of the Environment, Ontario. ISBN 07729-9248-7

Malvern Instruments Ltd., 1997. Installation Guide for Malvern Mastersizer 2000.

Marsalek. J, B.Brownlee, T. Mayer, S. Lawal, and G. A. Larkin, 1997. Heavy metals and PAHs in stormwater runoff from the skyway bridge, Burlington, Ontario. Water Quality Research Journal of Canada. V 32, No (4): pp815-827

Persaud, D., R. Jaagumagi, and A. Hayton. 1992. Guidelines for the protection and management of aquatic sediment in Ontario. Water Resources Branch, Ontario Ministry of Environment. Queen's Printer for Ontario, Toronto, Ontario, Canada.

Rochfort, Q., Grapentine, L., Marsalek, J., Brownlee, B., Reynoldson, T., Thompson, S., Milani, D., and Logan, C., 2000. Using Benthic Assessment Techniques to Determine Combined Sewer Overflow and Stormwater Impacts in the Auqatic Ecosystem. Water Quality Research Journal of Canada. V 35, No (3): pp365-397

Schroeter, H. O., 1997. Toxic Contaminant Loadings from Municipal Sources in Ontario Area of Concern, Water Quality Research Journal of Canada, 32, pp.7-22

Shokouhian. M. D, S. Ni; Chemosphere, 2001. Loading estimates of lead, copper, cadmium and zinc in urban runoff from specific sources.44: pp.997-1009

Soete, D., Gijbels, D., Renaat, R., and Hoste, J., 1972. Neutron activation analysis. Wiley-Interscience, New York.

United States Environmental Protection Agency, 1983. Results of the Nationwide urban runoff program. Water planning division, United States Environmental Protection Agency. PB 84-185552, Washington, D.C.

United States Environmental Protection Agency. 2004. The incidence and severity of sediment contamination in surface waters of the United States, National Sediment Quality Survey: Second Edition. USEPA.

Young, U. A., Wanielista, M. P., Harper, H. H., and Hvitred-Jacobsen, T., 1986. Best management practices - effectiveness of retention ponds for control of contaminants in highway runoff. Florida Department of Transportation, FL-ER-34-86 Final, Orlando, Florida. 